\title{
USING POLYETHER ETHER KETONE PARTICLES IN GFRP COMPOSITES FOR STRENGTHENING OF REINFORCED CONCRETE BEAMS
}

\author{
Sadegh Dardaei* \\ Assistant Professor, Faculty of Science and Technologies, \\ Tarbiat Modares University, Tehran, Iran \\ Hamed Bagheri \\ Assistant Professor, Faculty of Science and Technologies, \\ Tarbiat Modares University, Tehran, Iran \\ Niloufar Esmaeli \\ MSc. Student, Faculty of Science and Technologies, \\ Tarbiat Modares University, Tehran, Iran \\ *Corresponding Author
}

\begin{abstract}
One of the most common strengthening methods of structural elements is the use of Glass Fiber Reinforced Polymer (GFRP) composite. The two major components of a GFRP composite material is resin and reinforcement. A cured thermosetting resin without any reinforcement is glass-like in nature and appearance, but often very brittle. By adding a reinforcing fiber such as carbon fiber, glass, or aramid, the properties are vastly improved. The change in the properties of each of the components affects the general characteristics of GFRP. This research includes experimental and numerical studies. In the experimental part, the effect of two types of epoxy and polyesters resin in the mechanical properties of GFRP composite has been investigated. Then use of polyether ether ketone (PEEK) as an additive to modify the resin component in the GFRP and its effect on the mechanical properties of the composite is investigated. The strength and energy absorption of the samples were determined and compared. According to experimental results, a sample that has the best technical performance has been used in nonlinear finite element analysis. The aim of the numerical studies was to investigate the effect of GFRP composites on the overall behavior of a reinforced concrete beam. The analytical models include a reinforced concrete beam without strengthening, a reinforced concrete beam with GFRP strengthening, and a reinforced concrete beam with modified GFRP strengthening, with PEEK, are considered. The strength, ductility, and energy absorption of models were determined and compared.
\end{abstract}


Keywords: GFRP composite, epoxy resin, polyester resin, PEEK, numerical analysis, Reinforced concrete beam.

Cite this Article: Sadegh Dardaei, Hamed Bagheri, Niloufar Esmaeli, Using Polyether Ether Ketone Particles in GFRP Composites for Strengthening of Reinforced Concrete Beams. International Journal of Civil Engineering and Technology 11(1), 2020, 190-198.

http://iaeme.com/Home/issue/IJCIET?Volume=11\&Issue=1

\section{INTRODUCTION}

One of the most common methods for structural strengthening is the use of glass fiber reinforced plastic (GFRP) composites given their desirable mechanical characteristics such as high durability and resistance to exerted loads and environmental factors. Employing steel sheets is one of the most common methods for the retrofitting of reinforced concrete (RC) structures. Numerous studies have been recently conducted on the replacement of steel sheets with fiber-reinforced plastic (FRP) composites to retrofit RC structures [1-7]. The properties of the two constituents of FPR composites, namely matrix, and resin, can affect the general properties of FRP. The matrix used in FRP composites includes glass fibers, carbon, and aramid, the direction of which affects the FRP properties [8-15].

Epoxy and polyester resins are among the different resin types used in FRP composites. Accordingly, some studies investigated the effectiveness of different types of FRP composites in the optimization of different structural elements including beam and column. For example, Prabin Pathak et al. reinforced an RC beam using FRP composite and employed the finite element method (FEM) along with a nonlinear analysis to demonstrate its effectiveness in improving the mechanical strength of the beam [16]. Reviewing the literature on structural behavior showed that the modification of resin properties, as one of the most important elements of GFPR composite materials has been neglected so far [17,18]. This study investigated the experimental modification of different resins using polyether ether ketone (PEEK) as the additive, which is an artificial polymer capable of maintaining its mechanical properties at low and high temperatures. Accordingly, two different glass fibers and two different resins, including epoxy and polyester, were used to modify the composite properties of these elements. After demonstrating the effectiveness of PEEK in improving GFRP composites, the effect of modifying resin properties, by using the selected method, on the general behavior of an RC concrete beam retrofitted using GFRP was numerically investigated.

\section{EXPERIMENTAL STUDIES}

In this part, the effect of using epoxy and polyester resins on GFRP composites was experimentally investigated. Accordingly, the effect of using PEEK additives on the mechanical properties of glass composites was studied. Glass fibers were used due to their high tensile strength, high electrical resistance, impact resistance, resistance to environmental conditions, and availability compared to the other fibers. The fabrication process involved a control specimen (without PEEK) and PEEK-containing specimens.

\subsection{Materials}

In this study following materials were used: Glass fibers (unidirectional and bidirectional), Polyester PC was made from unsaturated polyester resin, a viscous liquid resin with a styrene monomer content of $41 \%$. Initiators are chemical compounds that decompose into free radicals that are responsible for the initiation of the polymerization process. The initiator used 
in polyester PC was methyl ethyl ketone peroxide (MEKP) and (die methyl phthalate) DMP. Cobalt naphthenate (6\% concentration) was the promoter used in polyester PC. Epoxy resin was EPO 828 from and hardener Teta both made in Mokarar Co. Iran. Polyether ether ketone granules were purchased from Sigma-Aldrich (MO. USA). Two dimensional E-glass with density $200 \mathrm{gr} / \mathrm{m}^{2}$ purchased from Colan Co. Australia.

\subsection{Composite Preparation}

For epoxy composite $100 \mathrm{gr}$ of resin was blended with $30 \mathrm{gr}$ of hardener and also blended with other reinforcement phases, then the samples were put into the oven for $3 \mathrm{hr}$ at $80 \mathrm{C}$. For polyester composite $100 \mathrm{gr}$ of resin was blended with $1 \mathrm{phr}$ of cobalt then $1 \mathrm{phr}$ of the A60 catalyst was added to the blend then other reinforcement materials were added to the blend. The preparation of the specimens and their size were based on the Iranian National Standard (ISIRI 14761-1) [19]. The specimens were divided into the control and modification groups. A total of 36 specimens were prepared and named as presented in Table 1.

Table 1 Samples and their codes

\begin{tabular}{|c|l|}
\hline \multicolumn{2}{|c|}{ Control samples } \\
\hline Code & \multicolumn{1}{c|}{ Sample } \\
\hline GE & The glass composites with epoxy \\
\hline GP & \multicolumn{1}{c|}{ The glass composites with polyester } \\
\hline MEP-5 & The glass composites with epoxy and 5\% PEEK \\
\hline GEP-10 & The glass composites with epoxy and 10\% PEEK \\
\hline GEP-15 & The glass composites with epoxy and 15\% PEEK \\
\hline GPP-5 & The glass composites with polyester and 5\% PEEK \\
\hline GPP-10 & The glass composites with polyester and 10\% PEEK \\
\hline GPP-15 & The glass composites with polyester and 15\% PEEK \\
\hline
\end{tabular}

Figure 1 shows the vulcanized glass composite specimens. Given the employed resin type, the fabrication methods were divided into the Room-Temperature-Vulcanizing (RTV) silicone and oven-vulcanizing methods. Fabrication of the control specimen included the following stages:

- The glass fibers were first cut according to the Iranian National Standard (ISIRI 14761-1) [19].

- The glass fibers were laminated with resin. This process was done by forward and backward movement of a roller, for which the resin was mixed with proper amounts of catalyst and hardener as suggested by the datasheet.

- The glass composites with polyester and epoxy resins were vulcanized, respectively, in an oven at $80^{\circ} \mathrm{C}$ and in the room temperature for one hour, respectively. 

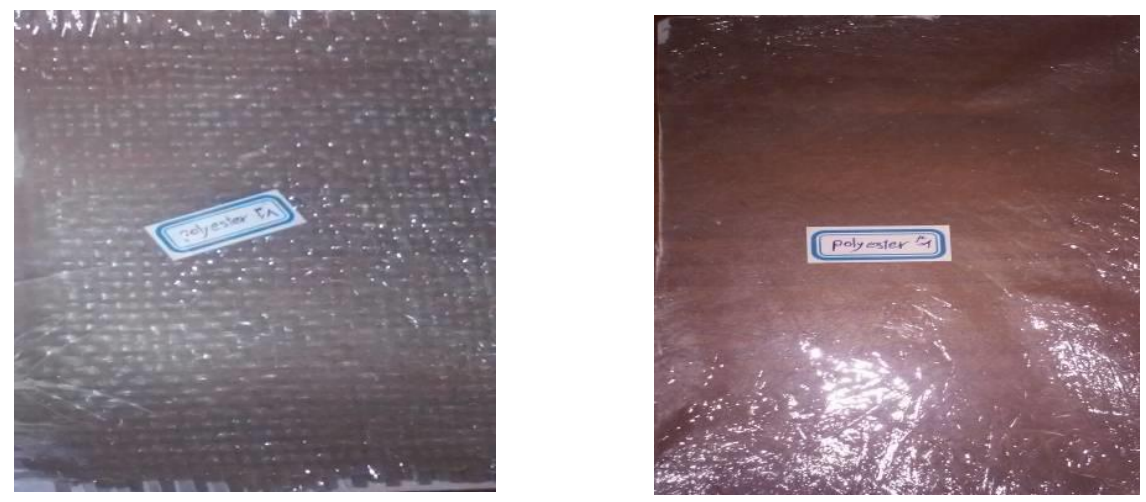

Figure 1. The vulcanized glass composite specimens

The only difference in fabricating the modified specimens was the use of PEEK additives. In the second stage when the resin was mixed with the hardener and catalyst, PEEK was added at an amount of $5 \%$ of the total resin volume. The specimens were then subjected to a tensile load according to ISIRI1476-1 [19] as follows:

- The transversal cross-section of the specimens was measured.

- The specimens were fixed in the gripper along with the acting force.

- The elongation rate of the strength tester device was set between 1-5 mm per minute. The tester devices then started applying load the specimen up to the rupture point. Figure 2 represents the tensile process of the employed 5-ton tester machine (Gotech, Taiwan).

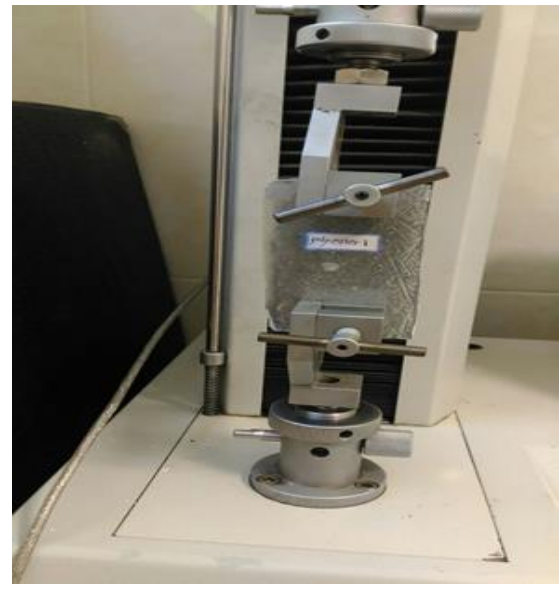

Figure 2. The tensile test

\subsection{Results and Discussion}

The ultimate strength and energy absorption of two control composites are shown in table 2 . Energy absorption is a different means to evaluate toughness and gains unanimity in decisions regarding the acceptance of the values obtained and is defined as the surface below the loaddisplacement curve. As it is seen the energy absorption of the epoxy composite is rather than about $11 \%$. This result comes from the better mechanical behavior of epoxy resin.

Table 2. The ultimate strength and energy absorption of control composites

\begin{tabular}{|c|c|c|}
\hline Sample Code & Ultimate strength (MPa) & Energy absorption (kgf.mm) \\
\hline GE & 0.44 & 168 \\
\hline GP & 0.57 & 150 \\
\hline
\end{tabular}


Figure 3 shows the stress-strain curves of glass composites incorporating epoxy and polyester resins. According to this figure, employing polyester resin in glass composites improved its strength, whereas the epoxy resin exhibited a more ductile behavior.

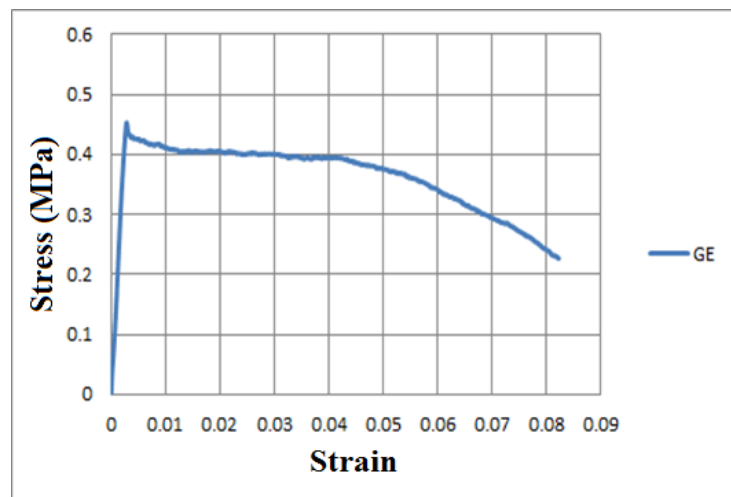

(A)

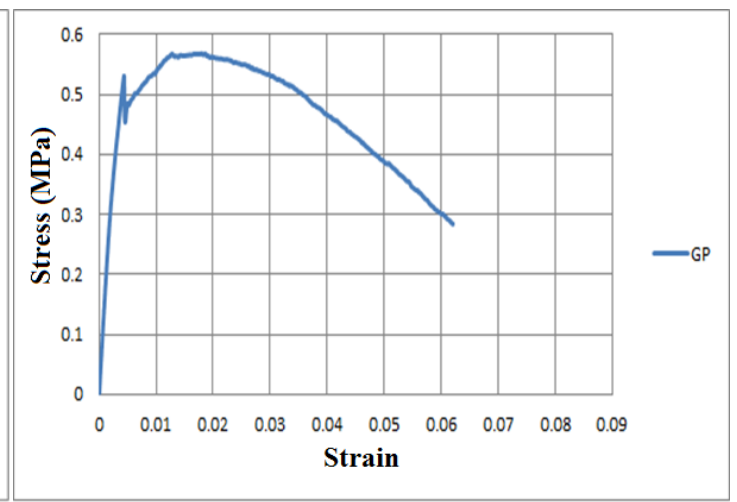

(B)

Figure 3. The stress-strain curves in control samples: (A) The glass composite with epoxy, (B) The glass composite with polyester

\subsection{Effect of PEEK on the Mechanical behavior of Composite}

Figures 4 shows the effect of using different percentage of PEEK, which generally improved the mechanical properties of the glass fiber composites containing polyester and epoxy resins, respectively.

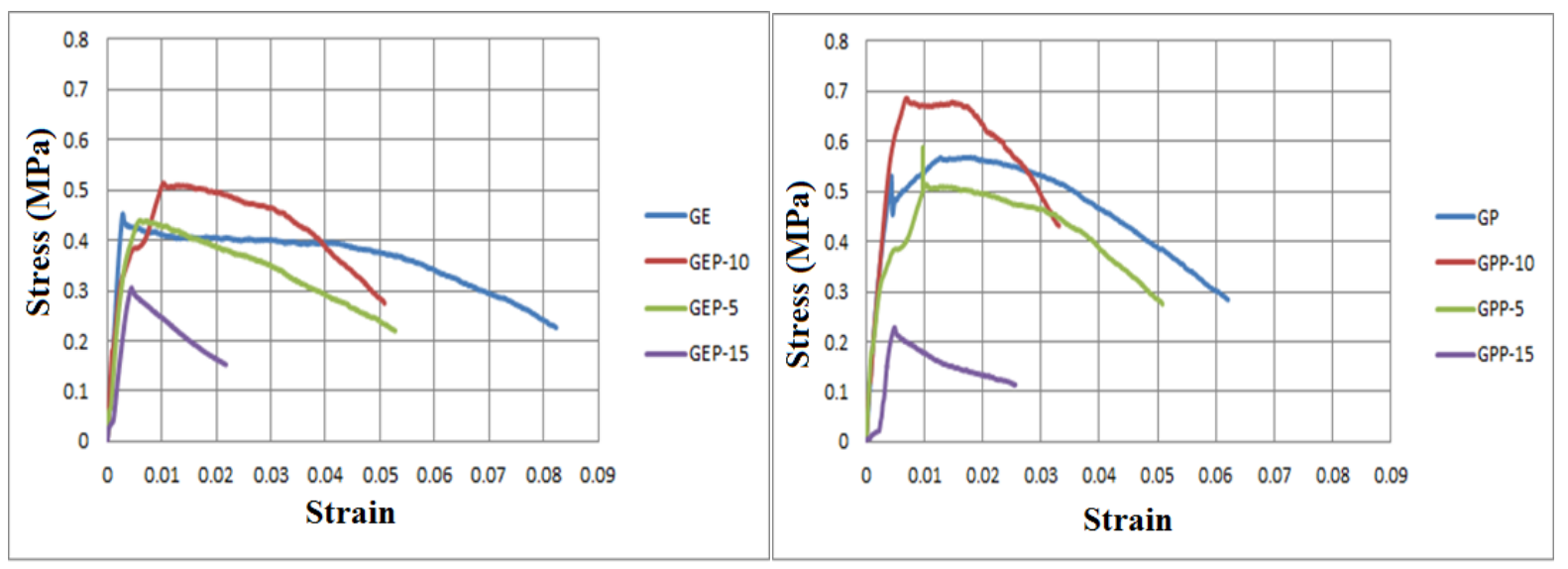

(A)

(B)

Figure 4. The stress-strain curves in modified samples: (A) The glass composites with epoxy, (B) The glass composites with polyester

As it can be seen in the stress-strain curves for polyester resin the strength of composite increase till $10 \%$ of PEEK then decrease when the percent of PEEK is $15 \%$ that this may be due to agglomeration of PEEK particle in the matrix. The same results can be seen in the composite with epoxy resin. Table 3 shows the results of energy absorption and ultimate of strength for both resin with 5,10 and $15 \%$ of PEEK. As it has been expected the result for epoxy resin is higher than of polyester resin that it may be due to the energy absorption of matrix strength. Also, it can be seen the effect of the dispersed phase on the polyester resin is higher than epoxy resin because the polyester is brittle than epoxy, so PEEK can change the behavior of resin from brittle to ductile. So the GPP-10 is selected as a superior method and is 
used for the numerical study because the effect of PEEK particle in this matrix is higher than the epoxy matrix.

Table 3. The ultimate strength and energy absorption of modified composites

\begin{tabular}{|c|c|c|c|c|}
\hline Sample & $\begin{array}{c}\text { Ultimate strength } \\
\text { (MPa) }\end{array}$ & $\begin{array}{c}\text { Energy absorption } \\
\text { (kgf.mm) }\end{array}$ & $\begin{array}{c}\text { Ultimate strength } \\
\text { changes (percentage) }\end{array}$ & $\begin{array}{c}\text { Energy absorption } \\
\text { changes } \\
\text { (percentage) }\end{array}$ \\
\hline GE & 0.44 & 168 & - & - \\
\hline GEP-5 & 0.45 & 180 & 2.3 & 11.9 \\
\hline GEP-10 & 0.51 & 200 & 16 & 19 \\
\hline GEP-15 & 0.3 & 30 & -31 & -82 \\
\hline GP & 0.57 & 150 & - & - \\
\hline GPP-5 & 0.58 & 165 & 1.75 & 10 \\
\hline GPP-10 & 0.68 & 210 & 19.3 & 27.3 \\
\hline GPP-15 & 0.21 & 20 & -63 & -86.6 \\
\hline
\end{tabular}

\section{NUMERICAL STUDIES}

The numerical studies were performed based on behavioral properties obtained from experimental studies. The aim of the numerical studies was to investigate the effect of GFRP composites on the overall behavior of reinforced concrete beam with a rectangular crosssection subject to a concentrated load at the center of the span. Three types of analytical models including a reinforced concrete beam without strengthening, a reinforced concrete beam with GFRP strengthening, and a reinforced concrete beam with modified GFRP strengthening, with PEEK, are considered. The models are presented in Table 4.

Table 4. Numerical models

\begin{tabular}{|c|l|}
\hline \multicolumn{2}{|c|}{ Control samples } \\
\hline Code & Sample \\
\hline CB & The reinforced concrete beam without strengthening \\
\hline GPB & The reinforced concrete beam with GFRP strengthening \\
\hline GPB-10P & $\begin{array}{l}\text { The reinforced concrete beam with modified GFRP } \\
\text { strengthening (10\% PEEK) }\end{array}$ \\
\hline
\end{tabular}

\subsection{Modeling}

For modeling the bars, the bilinear complete elasto-plastic is used. The kinematic hardening was used to define steel plasticity. There are different behavioral models for concrete in numerical modeling. In this paper, the continuum, plasticity-based, damage model was used. It assumes that the main two failure mechanisms are tensile cracking and compressive crushing of the concrete material. Under uniaxial tension, the stress-strain response follows a linear elastic relationship until the value of the failure stress is reached. The failure stress corresponds to the onset of micro-cracking in the concrete material. Beyond the failure stress, the formation of micro-cracks is represented macroscopically with a softening stress-strain response, which induces strain localization in the concrete structure. Under uniaxial compression, the response is linear until the value of the initial yield. In the plastic regime, the response is typically characterized by stress hardening followed by strain-softening beyond the ultimate stress [20]. For modeling of concrete elements, the elements are used by eight nodes having three degrees of freedom at each node. Under uniaxial pressure, the concrete strain related to the maximum stress is assumed to be 0.002 and the Poisson's ratio under uniaxial pressure was assumed to be 0.167. In GFRP composites, each layer under plane stress can be regarded as an orthotropic layer. Moreover, the uniaxial polymer fibers exhibit 
nonlinear behavior in the in-plane shear strain-stress relationship. The nonlinear behavior of GFRP was modeled via Hashin's failure model.

\subsection{Model Validation}

To validate the model, the concrete beam studied by Naserifat et al. was selected and modeled using a finite elements model [20]. The beam, with a single bar, was subjected to displacement-controlled loading, up to its ultimate capacity. Figure 5 represents the geometric properties of the beam and Table 5 present the material properties.

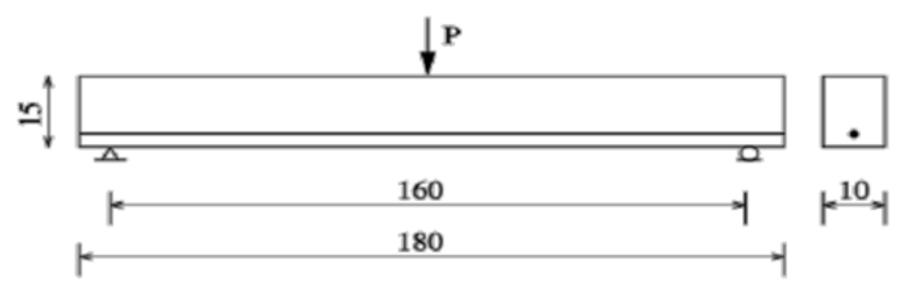

Figure 5: The modeled beam.

Table 5: Material properties

\begin{tabular}{|l|l|}
\hline \multicolumn{1}{|c|}{ concrete } & \multicolumn{1}{c|}{ steel } \\
\hline $\mathrm{f}_{\mathrm{c}}{ }^{\prime}=25\left(\mathrm{~N} / \mathrm{mm}^{2}\right)$ & $\mathrm{F}_{\mathrm{y}}=335\left(\mathrm{~N} / \mathrm{mm}^{2}\right)$ \\
\hline $\mathrm{E}_{\mathrm{c}}=31900\left(\mathrm{~N} / \mathrm{mm}^{2}\right)$ & $\mathrm{E}_{\mathrm{s}}=200000 \quad\left(\mathrm{~N} / \mathrm{mm}^{2}\right)$ \\
\hline $\mathrm{v}=0.2$ & $\mathrm{v}=0.3$ \\
\hline
\end{tabular}

After modeling the RC beam and conducting nonlinear static analysis, a comparison was made between results from the numerical model and the experimental beam to validate the numerical model. The results indicate that the results of the numerical analysis are consistent with the results of the experimental model. So the numerical model was set as our control beam (CB), and our analysis was done by reinforcing it with GFRP (GPB) and modified GFRP sheets (GPB-10P). The properties of the glass composite obtained from experiments were used in finite element models.

\subsection{Effect of GFRP Composite}

The results of numerical studies for CB, GPB, and GPB-10P are presented in figure 6 and Table 6. Based on these studies, it was found that GP composite increases the beam strength capacity by increasing the ultimate load of the beam from $27 \mathrm{kN}$ to $44 \mathrm{kN}$. Also, using the $10 \%$ PEEK in composite construction has increased the ultimate force of the beam from 44 $\mathrm{kN}$ to $52 \mathrm{kN}$, an increase of $18 \%$ in the beam capacity. As shown in the table, the energy absorption was approximately doubled in the case of GP composite strengthening, and by adding PEEK additive in the composite, the energy absorption rate was one and a half times. It also increases the beam ductility by $67 \%$ with respect to the values of the use of the GP sheet. Also, the use of $10 \%$ PEEK additive doubles the ductility of the beam reinforced with GP compared to the control beam. 


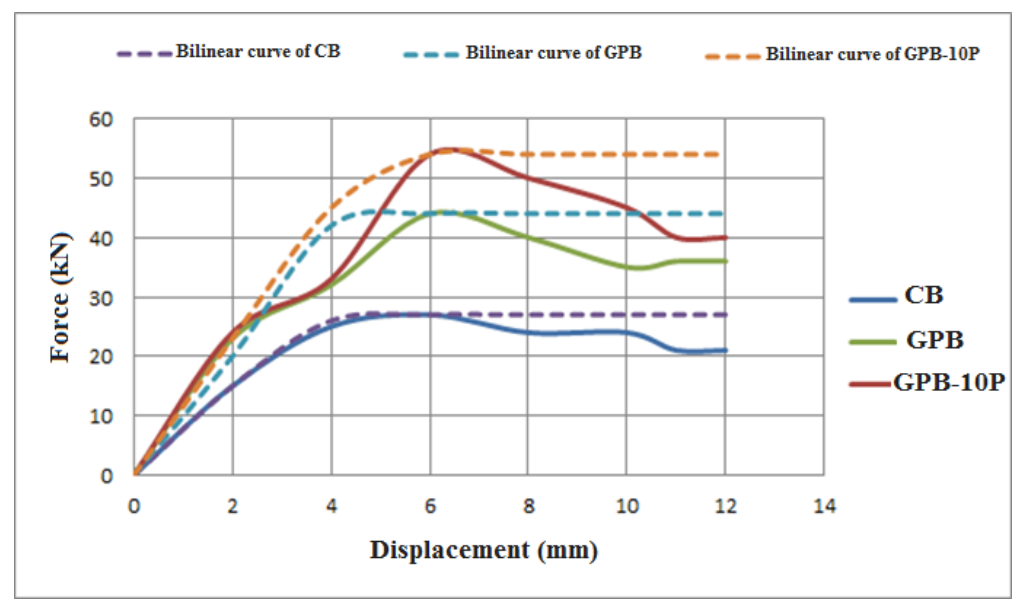

Figure 6: Response curves of models.

Table 6: Ultimate strength, Energy absorption, and Ductility of models

\begin{tabular}{|c|c|c|c|}
\hline Sample & $\begin{array}{c}\text { ultimate strength } \\
(\text { KN) }\end{array}$ & $\begin{array}{c}\text { energy absorption } \\
\text { (KN.mm) }\end{array}$ & ductility \\
\hline CB & 27 & 240 & 1.75 \\
\hline GPB & 44 & 504 & 2.92 \\
\hline GPB-10P & 52 & 660 & 5 \\
\hline
\end{tabular}

\section{CONCLUSION}

This research includes experimental and numerical studies. In the experimental part, the effect of two types of epoxy and polyesters resin in the mechanical properties of GFRP composite has been investigated, and then the use of polyether ether ketone (PEEK) as an additive to modify the resin component in the GFRP and its effect on the mechanical properties of the composite is investigated. The strength and energy absorption of the samples were determined and compared. Based on experimental studies, the result for epoxy resin is higher than of polyester resin that it may be due to the energy absorption of matrix strength. Also, it can be seen the effect of the dispersed phase on the polyester resin is higher than epoxy resin because the polyester is brittle than epoxy, so PEEK can change the behavior of resin from brittle to ductile. So the GPP-10 (The glass composites with polyester and 10\% PEEK) is selected as a superior method and is used for the numerical study. Based on numerical studies GP composite (The glass composites with polyester) increases the beam strength capacity by up to $62 \%$. Also, using the $10 \%$ PEEK in composite construction has increased the ultimate strength of the beam up to $18 \%$. Also, the energy absorption was approximately doubled in the case of GP composite strengthening, and by adding PEEK additive in the composite, the energy absorption rate was one and a half times.

\section{REFERENCES}

[1] Tamer El Maaddawy and Sayed Sherif (2009), "FRP composites for shear strengthening of reinforced concrete deep beams with openings", Structural Engineering Dept., Al-Wasl Al-Gadeed Consultants, Dubai, United Arab Emirates.

[2] Baky, H.A., Ebead, U.A., and Neale, K. W. (2007). "Flexural Behaviour of FRPStrengthened Reinforced Concrete beams," Journal of Composites for Construction, ASCE, 11(6), 629-639.

[3] Bousias, S.N., Triantafillou, T.C., Fardis, M.N., Spathis, L. and O'Regan, B.A. (2004). "Fiber-Reinforced Polymer Retrofitting of Rectangular Reinforced Concrete Columns with or without Corrosion", ACI Structural Journal, 101(4), 512-520. 
Using Polyether Ether Ketone Particles in GFRP Composites for Strengthening of Reinforced Concrete Beams

[4] Bonacci, J.F., and Maalej, M. (2000). "Externally bonded fiber-reinforced polymer for rehabilitation of corrosion damaged concrete beams", ACI Structural Journal, 97(5), 703711.

[5] Brena, S.F., Bramblett, R.M., Wood, S.L., and Kreger, M.E. (2003) "Increasing Flexural capacity of Reinforced Concrete Beams Using Carbon Fiber-Reinforced Polymers Composites", ACI Structural Journal, 100(1), 36-46.

[6] Buyukozturk, O., and Hearing, B. (1998) "Failure Behaviour of Precracked Concrete Beams Retrofitted with FRP", Journal of Composites for Construction, ASCE, 2(3), 138144.

[7] Colalillo, M.A., and Sheikh, S.A. (2009) "Seismic retrofit of shear-critical RC Beams using CFRP', Report no. FRPRCS-9, Sydney, Australia.

[8] H. Makhdoumi, A. Aryanezhad, R. Rahgozar;" The Effect of FRP Wrapping on Seismic Behavior of Concrete Frame Elements", $8^{\text {th }}$ International Conference on of Iran-Tehran- 51 Oct. 51.

[9] Mostofinejad, D. (2000), “An Overview on FRP Reinforced Concrete as Corrosion Resistant Element in Offshore Structures",4th International Conference on Ports\&Marine.

[10] H. F. IDEHLOO (2008) "Updated Design Pilosophy for Structural Strengthening of Concrete Structures with Fiber Reinforced Polymers (FRP)".

[11] Bedard, Claude, "Composite Reinforcing Bars (1992) "Assessing Their Use in Concrete," Concrete International, pp. 55-59.

[12] Mallick, P. K. (2007), "Fiber Reinforced Composites",

[13] Yashas Gowda, T.G.; Sanjay, M.R.; Subrahmanya Bhat, K.; Madhu, P.; Senthamaraikannan, P.; Yogesha, B. SSPolymer matrix-natural fiber composites: An overview. Cogent. Eng. 2018, 5,1446667.

[14] Sherif, G.; Chukov, D.; Tcherdyntsev, V.; Torokhov, V. (2019)" Eect of formation route on the mechanical properties of the polyethersulfone composites reinforced with glass fibers. Polymers", 11, 1364.

[15] Chukov, D.; Nematulloev, S.; Zadorozhnyy, M.; Tcherdyntsev, V.; Stepashkin, A.; Zherebtsov, D. Structure, (2019) "Mechanical and thermal properties of polyphenylene sulfide and polysulfone impregnated carbon fiber composites. Polymers", 11, 684.

[16] Prabin Pathak (2016) "Nonlinear Finite Element Analysis of FRP Strengthened RC Beams under Static and Cyclic Loads, School of Engineering and Information Technology, University of New SouthWales Canberra, Australia.

[17] Larsson, F. (1986), "The Effect of Ultraviolet Light on Mechanical Properties of Kevlar 49 Composites", vol. 5, issue 1, pp. 19-22.

[18] Razaqpur, A. G., and Kashef, A. H., (1993) "State-of-the-Art on Fiber Reinforced Plastics for Buildings", Institute for Research in Construction - National Research Council of Canada, Carleton University.

[19] Iranian Institure of standards and industrial research (2018), "Fiber-reinforced polymer (FRP) for reinforcement of concrete- Test Methods Part 1: FRP bars and grids" Standard No: ISIRI 14761-1.

[20] Naserifar et al., (2009), "Nonlinear Finite Elment Analysis of reicnforced concrete beam retrofitted by FRP", $8^{\text {th }}$ International Congress on Civil Eng., Shiraz, Iran (in persian) 